\title{
AS ORIGENS IDEOLÓGICAS DA GUERRA SUJA NA ARGENTINA
}

\author{
Odilon Caldeira Neto \\ Mestre - UFRGS \\ E-mail: odiloncaldeiraneto@gmail.com
}

FINCHELSTEIN, Federico. The Ideological Origins of the Diry War: Fascism, Populism and Dictatorship in Twentieth Century Argentina. Oxford: Oxford University Press, 2014. 214 p.

Como foi possível a Argentina, uma nação fundada sobre preceitos liberais, ser palco de radicalismos políticos tão danosos, que envolveram e acarretaram em sequestros de bebês, assassinatos com motivação política, perseguições antissemitas, atentados a bomba e uma espécie de "tutela legitimadora" estabelecida em conjunção, sob o signo da cruz (Igreja) e da espada (forças armadas)? De que modo a história política argentina do século XX foi marcada por uma espécie de simbiose entre o contexto global do fascismo transatlântico e uma constante prática de adaptação e reformulação à realidade local? Essas, embora não somente, são algumas questões que movem Federico Finchelstein em "The Ideological Origins of the Dirty War: Fascism, Populism, and Dictatorship in Twentieth Century Argentina" (Oxford University Press, 2014, $1^{\text {a }}$ edição).

Em "Transatlantic Fascism: Ideology, Violence, and the Sacred in Argentina and Italy, 1919-1945" (2010), Federico Finchelstein já estabelecera análise sobre alguns dos elementos caros à história política argentina do século XX: a circularidade de ideias e colaborações intelectuais para e com o fascismo internacional (em especial o italiano), assim como o impacto desse processo naquela que é, na América Latina, a nação com maior incidência da imigração e presença europeia em seu ethos social. Em "Ideological Origins of the Dirty War", o objetivo do autor é maior e mais exaustivo, seja do ponto de vista da temporalidade, mas também da complexidade do tema.

Estabelecido o problema - ou, como compreender as motivações que perduraram e deram consistência ideológica, política e organizativa ao terrorismo de Estado das chamadas

Oficina do Historiador, Porto Alegre, EDIPUCRS, v. 7, n. 2, jul./dez. 2014, p. 247-254 
"Guerras Sujas" da última ditadura argentina, Finchelstein busca analisar esse processo de um modo não meramente descritivo, senão em sua historicidade. Para compreender, portanto, como a Argentina dos anos 1970 vivenciou a escalada de violência de extrema-direita, fosse aquela de Estado ou para-oficial, é estabelecida uma análise sobre a fundação da nação argentina moderna, seus mitos e "pais fundadores", assim como parte desse referencial foi consecutivamente manejado por uma radicalização nacionalista que estabeleceu um tipo específico de fascismo sacralizado, onde o desígnio divino imprimiria uma prática política persecutória em aliança entre jovens, intelectuais, políticos, lideranças militares e eclesiásticas em defesa de uma suposta devolução da Argentina à "civilização cristã”.

A lógica da Guerra Sucia, construída não enquanto uma guerra entre dois lados dispostos (ou em embate direto e determinado), mas sim em uma "disputa" entre perseguidores e perseguidos, possibilita ao autor compreender este processo e fato histórico dentro de uma perspectiva diversa. Dessa maneira, Finchelstein empreende uma análise sob conexões e interações variadas (ou um caldo político, religioso e cultural) que remonta justamente aos valores fundamentais na multiplicidade constituinte do próprio fenômeno do fascismo na Argentina.

Logo na introdução da obra, o autor demonstra estar ciente da complexidade histórica atribuída pelo recorte temporal estabelecido, pois, afinal de contas, está a se tratar de uma análise que abarca o contexto da emergência do fascismo em fenômeno internacional e transnacional, o contexto do entreguerras, o fracasso do fascismo (enquanto via política institucional e inspirativa para as direitas ao redor do mundo), além da emergência da Guerra Fria e seus desdobramentos, etc. E, em se tratando de uma história política argentina (e consequentemente latino-americana), há a preocupação em compreender os fluxos de interação, apropriação e reformulação das tendências europeias às realidades locais, assim como a criação de práticas e costumes políticos locais, tal qual o populismo peronista e também as disputas que dizem respeito mais à realidade local do que um contexto generalizante quase absoluto possa compreender.

Essa miríade constituinte do próprio problema-pesquisa direciona o autor a evidenciar a busca por uma rigidez conceitual fortuita. Afinal de contas, para dissociar a compreensão do fascismo enquanto uma espécie de vulgata ausente de perspectiva teórica e analítica definida ou, em outras palavras, para que o criticismo analítico não possa vir a dar lugar a uma instrumentalização política do termo (que pouco ou nada teria a oferecer para a compreensão do problema), Finchelstein demonstra clareza no sentido de tentar compreender a história

Oficina do Historiador, Porto Alegre, EDIPUCRS, v. 7, n. 2, jul./dez. 2014, p. 247-254 
política argentina do século XX distante de uma simples "denunciação" de um mimetismo ou anacronismo fascista à Argentina.

Isso implica, portanto, em observar que, embora as variadas ditaduras e organizações de extrema-direita argentinas possam ter proposto, imaginado ou efetivado alguma aproximação aos fascismos europeus (o italiano e alemão, em especial), os contextos em que se deram, e principalmente a busca pelo ineditismo e especificidade argentina deram tom não somente a um caso único, mas também à possibilidade de compreender como esse processo referencia elementos historicamente antecedentes ao fascismo internacional propriamente dito, e persistiu inclusive quando os "ex-fascistas" europeus tratavam de tentar explicar, resolver ou negar um passado persistente.

Dessa maneira, então, a obra aborda a história de uma persistência insistente e os trágicos resultados - a persistência fascista na Argentina, mesmo no após 1945, suas tentativas de inserção nos aparelhos de Estado, e como isso auxiliou a engendrar um processo histórico e político que culminou na Guerra Sucia. Essa persistência foi possível, nota o autor, justamente pela noção de fascismo genuinamente argentino (também chamados genericamente de "nacionalistas") que emergiu em um amálgama entre organizações influenciadas pelo fascismo do entreguerras e a apropriação e distorção dentro desse processo de sacralização política local. Em outras palavras, um certo de tipo de fascismo sob o auspício da cruz e da espada.

O autor busca romper, dentro desse intuito de pesquisa, com uma tradição presente em análises midiáticas (mas também em algumas correntes historiográficas e das ciências sociais) que trazem consigo um elemento relativamente "paternalista" em suas concepções laborais (e talvez também em uma visão de mundo), segundo o qual intelectuais de um país da América Latina não seriam capazes de criar uma forma autenticamente genuína ou inédita de autoritarismo político.

Isso não implica, claro, em alguma espécie de louvor às experiências autoritárias latino-americanas, tampouco na negação de qualquer fluxo e colaboração transatlântica na constituição dessas práticas, mas sim na compreensão que a prática de criação de uma via e modus autoritário de direita foi além de qualquer mimetismo típico de alguma mentalidade colonizada - e isso auxilia a explicar a sua penetração e persistência ao longo da história política argentina. Em contrapartida, essa perspectiva rompe também com a premissa analítica que busca imputar ao imperialismo enquanto força motriz proveniente e criadora de todo e qualquer mal existente em algum contexto nacional.

Oficina do Historiador, Porto Alegre, EDIPUCRS, v. 7, n. 2, jul./dez. 2014, p. 247-254 
Portanto, se o ocorrido durante a última ditadura argentina está além da "simples" adaptação e implantação daquilo que foi desenvolvido nos laboratórios políticos, intelectuais e militares norte-americanos e franceses durante a Guerra Fria, e também não se trata somente de alguma espécie de mimetismo do fascismo europeu no entre guerras, é necessário, dessa maneira, buscar a ancestralidade histórica circunstancial para a constituição desse fenômeno na história política Argentina do século XX, e de que modo atravessou, sob diversas roupagens políticas, diferentes contextos históricos. A obra se apresenta, deste modo, dividida em dois eixos principais: a análise sobre a gênese do pensamento autoritário nacionalista de direita argentino entre os anos 1900 e 1940, com ênfase na questão fascista e antissemita, e as reminiscências, continuidades e adaptações deste fenômeno durante o peronismo, os grupos paramilitares existentes durante os anos 1960 e 1970 e a lógica persecutória em prática em meio ao terrorismo de Estado da última ditadura militar argentina.

O capítulo 1, intitulado "The Ideological Origins of Fascist Argentina”, estabelece uma síntese e análise histórica sobre a forma como intelectuais imaginaram a nação argentina, em suas variações "inclusivas" e "exclusivistas", e mesmo como numa perspectiva mais liberal de nação imaginada, havia a presença de um certo repúdio às populações nativas locais. Isso evidencia, portanto, a dialética presente no processo de construção nacional, que mesmo sob os preceitos da modernidade, trouxe consigo elementos para a formação de uma base ideológica genocida (não tributável somente à questão argentina, evidentemente), e o processo de não assimilação à identidade nacional e execução indígena.

Essa concepção exclusivista de nação, ainda no fim do século XIX, auxiliou, conforme nota o autor, a estruturar a base de um pensamento nacionalista de direita em uma ideia de nação essencial restritiva. A noção da nacionalidade argentina enquanto residente não necessariamente em ideias, tradições e criações, mas algo mais próximo ao sangue, foi marcante para a criação da compreensão de uma Argentina essencialmente europeia, portanto supostamente elevada.

Após o processo de estruturação e disseminação dessas bases ideológicas em círculos intelectuais, militares, políticos e religiosos, a primeira ditadura argentina, de José Felix Uriburu, marca o momento da presença deste pensamento no Estado argentino. Embora, pondera Finchelstein, Uriburu não fosse evidentemente um fascista (transitava constantemente entre o fascismo e o conservadorismo autoritário), contava com apoio dos intelectuais nacionalistas de inspiração e filiação fascista, que acreditavam ser Uriburu uma figura política proeminentemente fascista.

Oficina do Historiador, Porto Alegre, EDIPUCRS, v. 7, n. 2, jul./dez. 2014, p. 247-254 
De qualquer maneira, a figura de Uriburu, sua queda e morte, foram circunstanciais para a radicalização das práticas políticas do fascismo argentino, e o diálogo e cooperação entre diversas correntes que, embora relativamente divergentes, concordavam em um profundo militarismo e um relacionamento simbiótico para com o catolicismo (e suas relações diversas no âmbito do fascismo transatlântico). O mito político criado em torno de Uriburu tornou-se um elemento de concentração política e a base do discurso legitimador dos posteriores golpes militares.

O capítulo 2, intitulado "Catholic Fascist Ideology in Argentina" compreende uma análise sistemática sobre a relação umbilical entre o pensamento fascista em contexto global (ou transatlântico, entre Argentina e Europa), e as dimensões católicas locais na sistematização da crença de um nacionalismo enquanto sentimento e razão ou, em outras palavras, como o fascismo na Argentina se criou com bases em uma sacramentalidade do radicalismo e violência política de inspiração fascista.

Essa análise auxilia a compreender, inclusive, os espaços e níveis de interação entre os fascistas locais e os italianos e alemães, e como que, mesmo num espaço de interação e circularidade intelectual no fascismo enquanto fenômeno transnacional, havia a preocupação constante na formação e solidificação da especificidade argentina neste processo. A variante específica argentina no fascismo internacional foi fundada, imaginada e estruturada, portanto, sob as bases da cruz e da espada, amparada no mito de Uriburu e com a tutela da tradição cristã dentro de uma concepção de nação.

Ao estabelecer a violência política sob a junção entre a tradição católica e a modernidade política do fascismo, as implicações messiânicas no fascismo argentino tornavam-se evidentes. Da mesma maneira, essa violência política buscava legitimação dentro de uma lógica de violência defensiva, segundo a qual a defesa desse "fascismo religioso" (e por consequência, da nação Argentina e da tradição cristã em dimensão universal), lançava as bases para uma guerra contra os "inimigos" dessa visão de mundo, ou todos e todas aquelas que duvidassem e buscassem subverter a imagem sagrada de uma nação católica, suas forças armadas e seu fascismo cristianizado.

O capítulo 3 (“Anti-Semitism, Sex, and Christianity), é dedicado a compreender a construção e difusão do antissemitismo político na Argentina no período. Embora o autor ressalte que o antissemitismo não havia sido uma novidade tributável a um marco fundador possível em Uriburu, foi entre as décadas de 1930 e 1940 que a questão antissemita toma proeminência política na Argentina. Seguindo a lógica própria do fascismo argentino, a

Oficina do Historiador, Porto Alegre, EDIPUCRS, v. 7, n. 2, jul./dez. 2014, p. 247-254 
questão antissemita, embora sob evidente instrumentalização política, se ancorou em uma concepção dual de mundo entre um binômio de estrato religioso.

Dessa maneira, a tradição judaica e os judeus (e suas "ramificações" imaginadas) seriam a prática e representação de um mundo carnal, terreno e hipersexualizado, contra a espiritualidade sublime residente na tradição católica e, por essa razão, também na identidade argentina. Sendo assim, o aspecto clerical do fascismo argentino construiu uma máquina antissemita que aliava o aspecto religioso ao político, em suas peças de divulgação, propaganda, assim como nos livros, periódicos, etc.

No capítulo 4, intitulado "Peronist Populism and Fascism", Federico Finchelstein empreende uma rígida análise sobre a questão do fascismo no e durante o peronismo enquanto prática populista tipicamente latino-americana e, por isso, essencial para a compreensão da história política argentina. Partindo do princípio da compreensão do peronismo distante de alguma espécie classificável ou variável de fascismo, o autor demonstra como os fascistas argentinos buscaram se inserir dentro das estruturas do peronismo, e com algum sucesso.

E apesar das bases históricas, ideológicas e sociais do peronismo serem diferentes ou divergentes às do fascismo histórico e genérico em contexto global, é possível observar como o próprio Perón buscou compreender a realidade e o fracasso político do fascismo na Europa, para criar uma estratégia e forma política própria e relativamente autônoma. Embora Perón tenha mantido algumas práticas que teoricamente seriam de agrado aos fascistas argentinos, fato é que o peronismo enquanto fenômeno político foi substancial para a transformação da cultura política argentina, além daquilo que os próprios nacionalistas e fascistas argentinos poderiam desejar.

Conforme demonstra Finchelstein, Perón se apropriou de algo do fascismo histórico (o que não implica em afirmar algum fascismo no peronismo), do contexto da Guerra Fria e também de uma tradição nacionalista autoritária argentina. Essa formação diversificada auxilia a compreender, portanto, apesar das evidências inspirativas, a não efetivação de qualquer fascistização em Perón, e também a dubiedade dos fascistas argentinos para com o líder político argentino.

Esse contexto histórico ilumina, portanto, a compreensão sobre as relações dos fascistas e do fascismo argentino em relação ao peronismo e a vida local. A cisão, modificação, absorção ou radicalização política de algumas correntes do nacionalismo argentino de inspiração fascista se deu de modo ainda mais evidente durante e após o governo de Perón e, de um modo mais genérico, em relação ao próprio peronismo. $\mathrm{O}$ capítulo 5 do 
livro, "Bombs, Death and Ideology: From Tacuara to the Triple A", busca analisar a radicalização política dos fascistas argentinos, e suas táticas de entrismo junto ao peronismo (ou, em outro sentido, a tentativa de fascistização do peronismo e do cenário político argentino).

O golpe político contra Perón estabeleceu uma nova fase para a tradição política fascista argentina, de modo que é possível constatar isso dentro da persistência de simbologias, retóricas e ritualísticas fascistas na Tacuara, mesmo após o fim do fascismo histórico e de um evidente panorama internacional de desfascistização. Isso não significa, claro, que os fascistas argentinos à época estavam alheios aos panoramas históricos e realidades internacionais que os cercavam, e prova disto é o processo de adoção do "antissionismo" enquanto bandeira de agitação política e disseminação antissemita (além de cooperação com militantes das Ligas Árabes).

De Tacuara à Triplo A (Aliança Anticomunista Argentina), a escalada de violência em grupos e correntes que se aproximavam ou nominalmente se afiliavam a tradição histórica do fascismo argentino é evidente. Por sua vez, esse processo auxilia a compreender a especificidade argentina no tocante ao capítulo 6, intitulado "State Terrorism: the Ideology of the Argentina dictatorship".

Tal qual disposto na introdução da obra, Finchelstein objetiva atentar à especificidade na história política argentina. Se uma leitura "paternalista" ou "denunciativa" (quanto aos desígnios quase absolutos de um imperialismo) em relação à fundação do fascismo à argentina pouco auxiliariam na compreensão do fenômeno, o mesmo se dá no que diz respeito ao terrorismo de Estado na última ditadura argentina. Dessa maneira, portanto, o autor observa que tributar somente às inspirações francesas e norte-americanas nas doutrinas de segurança nacional quanto ao terrorismo de Estado, compreenderia um equívoco. Para Finchelstein, o estado de violência estabelecido no período teria origens diversas (argentinas, europeias, norte-americanas e latino-americanas), portanto mais complexas do que qualquer simplificação possa fazer parecer.

Conforme observa Finchelstein, a última ditadura argentina não foi, claro, uma ditadura fascista. Todavia, por meio de análise sobre atos, ações, retóricas, processo de sacralização política e também de trajetórias pessoais (em especial da formação intelectual e política de alguns militares do período), é possível compreender a gênese da violência política por meio da estrutura analítica apresentada durante a obra. Os processos de “desaparecimentos", aliados à existência de campos de concentração durante a ditadura não

Oficina do Historiador, Porto Alegre, EDIPUCRS, v. 7, n. 2, jul./dez. 2014, p. 247-254 
foram mero desígnio momentâneo das conjecturas políticas locais ou internacionais, senão fruto e persistência de um processo ao longo do século XX, em âmbito local mas também sob ligações transatlânticas.

Nesse sentido, Finchelstein apresenta uma exaustiva análise (apesar do caráter relativamente sintético da obra) da história política argentina durante o século XX, em especial sob o ponto de vista do caráter fortuito da rigidez teórica apresentada - e talvez esta seja uma das principais contribuições da obra para a historiografia do tema e afins. Dessa maneira, portanto, compreender a presença de um elemento fascista dentro da histórica recente argentina não se trata de uma simples acusação em torno da instrumentalização política de um termo ou conceito, mas sim da busca por compreensão da casualidade histórica, e os resultados desse processo para a Argentina (e também para a América do Sul). Por fim, o autor sinaliza para algo que merece atenção detalhada: qual o papel desses traumas, ressentimentos políticos e fragmentação da extrema-direita na Argentina atual? A questão permanece aberta, assim como a necessidade de esforços de pesquisa.

RESENHA ENVIADA EM: 27/10/2014 ACEITA PARA PUBLICAÇÃO EM: 07/11/2014 